\title{
EXPERIMENTAL STUDIES \\ OF FAST WAVE PROPAGATION \\ IN DIII-D
}

by

H. IKEZI, R.I. PINSKER, S.C. CHIU,

and J.S. deGRASSIE

JUNE 1995

DISTRIBUTION OF THIS DOCUMENT IS UNLIMITED 


\section{DISCLAIMER}

This report was prepared as an account of work sponsored by an agency of the United States Government. Neither the United States Government nor any agency thereof, nor any of their employees, makes any warranty, express or implied, or assumes any legal liability or responsibility for the accuracy, completeness, or usefulness of any information, apparatus, product, or process disclosed, or represents that its use would not infringe privately owned rights. Reference herein to any specific commercial product, process, or service by trade name, trademark, manufacturer, or otherwise, does not necessarily constitute or imply its endorsement, recommendation, or favoring by the United States Government or any agency thereof. The views and opinions of authors expressed herein do not necessarily state or reflect those of the United States Government or any agency thereof. 


\section{DISCLAIMER}

Portions of this document may be illegible in electronic image products. Images are produced from the best available original document. 


\title{
EXPERIMENTAL STUDIES \\ OF FAST WAVE PROPAGATION \\ IN DIII-D
}

\author{
by \\ H. IKEZI, R.I. PINSKER, S.C. CHIU, \\ and J.S. deGRASSIE
}

This is a preprint of a paper presented at the 11th Topical Conference on Radio Frequency Power in Plasmas, May 17-19, 1995, Palm Springs, California, and to be printed in the Proceedings.

\author{
Work supported by \\ U.S. Department of Energy \\ Contract DE-AC03-89ER51114
}

\section{GENERAL ATOMICS PROJECT 3466}

JUNE 1995

DISTRIBUTION OF THIS DOCUMENT IS UNLIMITED 


\title{
Experimental Studies of Fast Wave Propagation in DIII-D
}

\author{
H. Ikezi, R.I. Pinsker, S.C. Chiu, and J.S. deGrassie
}

General Atomics, San Diego, California 92186

\begin{abstract}
Fast Alfvén waves radiated from the phased array antenna in the DIII-D tokamak and used for heating and current drive are studied by employing a $\dot{B}$-loop array mounted on the vacuum vessel wall. The wave propagation direction controlled by the antenna phasing is clearly observed. A small divergence of the rays arising from the anisotropic nature of the fast wave is found. Comparison with a ray tracing code confirms that the ray position calculated by the code is accurate up to at least one toroidal turn of the rays. Conservation of $R k_{\mathrm{t}}$ which is a basic assumption in computer codes is tested. Although the upshift of toroidal wavenumber $k_{\mathrm{t}}$ at small major radius $R$ is confirmed, $R k_{\mathrm{t}}$ is not well conserved. A mass density interferometer is demonstrated by employing the extraordinary fast wave.
\end{abstract}

We have studied experimentally the fast wave propagation in the DIII-D tokamak. The motivation of this work is to find (i) if the wavenumber and if the ray directions are controlled by the antenna phasing in the intended manner and if the ray position predicted by the ray tracing is correct, (ii) if the conservation of toroidal wavenumber, the basic assumption in the computations, is valid, and (iii) if any spurious waves such as surface waves are excited.

DIII-D has three phased array antennas for fast wave radiation [1]. We report the results from the experiments employing one of them. This antenna is on the outboard at the midplane of the vacuum vessel and consists of four current-carrying straps which are separated by $0.24 \mathrm{~m}$ toroidally. A boron carbide coated Faraday shield is in front of the antenna straps. The wave frequency is $60 \mathrm{MHz}$ and the ion cyclotron frequency is 7 to $15 \mathrm{MHz}$. 
The wave magnetic field is detected by the $\dot{B}$-loops which are on both outboard and inboard walls of the vacuum vessel. A pair of loops is on the outboard wall at $\phi=130 \mathrm{deg}$ and $-130 \mathrm{deg}$ to detect both toroidal and poloidal wave $B$ field. The toroidal angle $\phi$ is chosen to be $0 \mathrm{deg}$ at the center of the antenna and is positive clockwise from a top view. The loops on the inboard wall are positioned at $\phi= \pm 37.5, \pm 15$, and $0 \mathrm{deg}$.

The signals from the loops are fed to an interferometer which gives two outputs, $c$ and $s$, for each loop signal $f(t)$, which are the correlations between $f(t)$ and the reference signals $\cos \omega t$ and the 1/4-cycle delayed sin $\omega t$ which are derived from the master oscillator for the $\mathrm{rf}$ transmitter. The angle $\Phi=\tan ^{-1}(s / c)$ gives the phase delay during the wave propagation in the plasma $\int \vec{k} \cdot d \vec{r}$ where the integral is taken along the ray connecting the antenna and the $\dot{B}$-loop.

The phase velocity of the fast wave propagating across the magnetic field equals the Alfvén velocity in our low $\beta$ plasma. The wave phase shift with respect to the phase in vacuum is measured throughout the discharge. The line-averaged plasma mass density is then obtained. An example is plotted in Fig. 1 (smooth curve). The density from the DIII-D $\mathrm{CO}_{2}$ laser interferometer is also plotted (noisier curve). Two curves agree with each other well, indicating that the waves launched and detected are fast waves.

Our measurements verify that the ray directivity varies with the phasing at the antenna. An example of ray behavior is shown in the following. The interferometer outputs from two antenna phasing $(0,0, \pi, \pi)$ and $(0, \pi / 2, \pi,-\pi / 2)$ are shown in Fig. 2. The inboard loop at $\phi=0$ receives no single-pass signal indicating that the antenna lobe is directed sideways. The outboard loops at $\phi= \pm 130 \mathrm{deg}$ receive equal amplitude but opposite sense, when the phasing is $(0,0, \pi, \pi)$ as we find on the third and fourth traces of Fig. 2(a). Thus the antenna is radiating antisymmetrically.

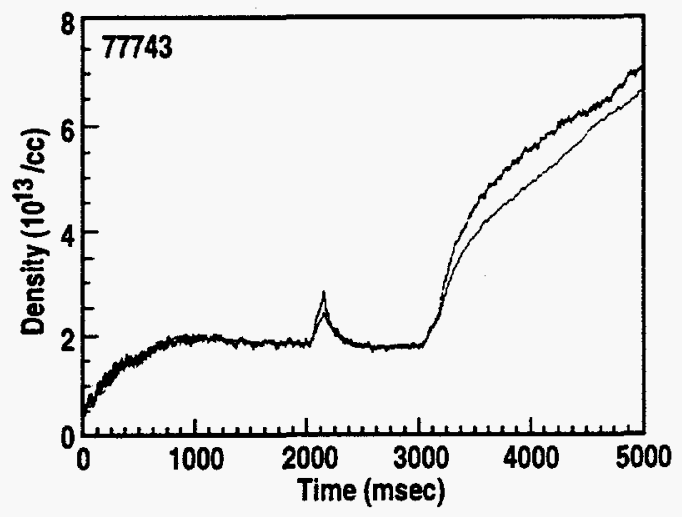

FIGURE 1. The plasma density obtained by $\mathrm{CO}_{2}$ interferometer (noisier curve) and by extraordinary fast wave interferometer (quieter curve). $B_{t}=2.1 \mathrm{~T}$, $I_{\mathrm{p}}=0.8 \mathrm{MA}$. 


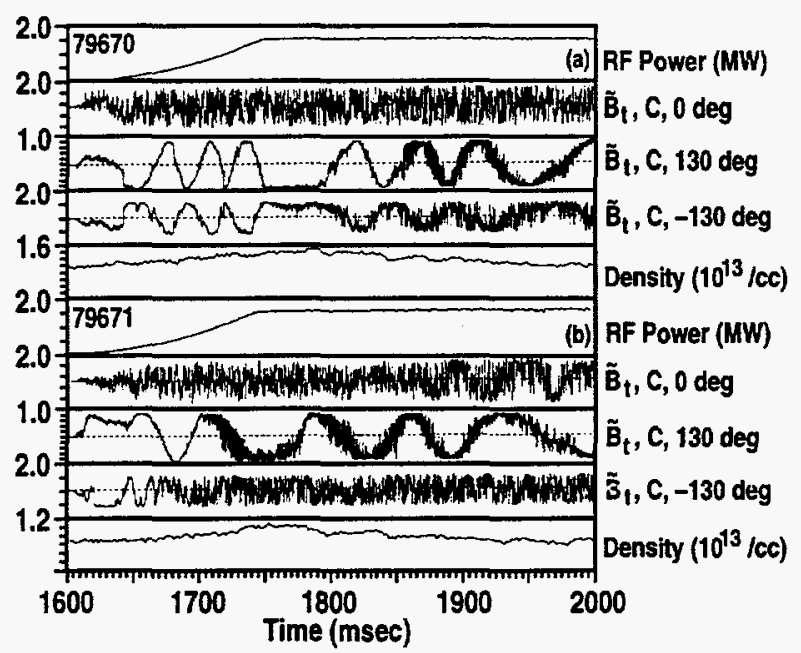

FIGURE 2. The interferometer outputs when the antenna phasings are $(a)(0,0$, $\pi, \pi)$ and (b) $(0, \pi / 2, \pi,-\pi / 2)$.

The fast wave phase velocity is scaled by $v_{\mathrm{A}} / c$ in all directions, so that the phase shift is proportional to (plasma density) ${ }^{1 / 2}$ in all propagation directions. The estimated phase shift due to the change of density agrees with the observation if one assumes that the ray from the antenna goes directly to the outboard loops.

Switching to current drive phasing $(0, \pi / 2, \pi,-\pi / 2)$ does not alter the signal from $\phi=130 \mathrm{deg}$, but the signal from $-130 \mathrm{deg}$ is changed entirely as shown in Fig. 2(b). The current driving ray which is going to the positive $\phi$ is preserved, while the ray going oppositely disappears.

The product of toroidal wavenumber and major radius $k_{\mathrm{t}} R$ is conserved in the toroidally symmetric plasma. The ray tracing [2] and full wave [3] computer codes assume $k_{\mathrm{t}} R=$ constant. We have tested if this assumption is valid.

Figure 3 shows the $k_{\mathrm{t}}$ spectra derived from the inboard probes for three different antenna phasings, $(0,0,0,0)$ in $(a),(0, \pi / 2, \pi,-\pi / 2)$ in (b), and $(0,-\pi / 2, \pi, \pi / 2)$ in (c). We first find that $k_{\mathrm{t}} / 2 \pi \simeq \pm 2 / \mathrm{m}$ for co- and counter current drive phasing. This is $k_{\mathrm{t}}$ on the inboard where major radius $R$ equals $1 \mathrm{~m}$. On the other hand, $k_{\mathrm{t}} / 2 \pi= \pm 1.04$ is estimated at the position of antenna from the antenna strap separation of $0.24 \mathrm{~m}$. The major radius of antenna position, $R=2.32 \mathrm{~m}$, gives $R k_{\mathrm{t}} / 2 \pi=2.4$ which is somewhat larger than the observed value on the inboard which is about 2 , but a clear upshift of $k_{\mathrm{t}}$ at the inboard is found.

There are higher power portions in the spectra of co- and counter current drive phasings. These are the portions where the inboard loop array detects the wave which traveled a single toroidal turn. The lower 


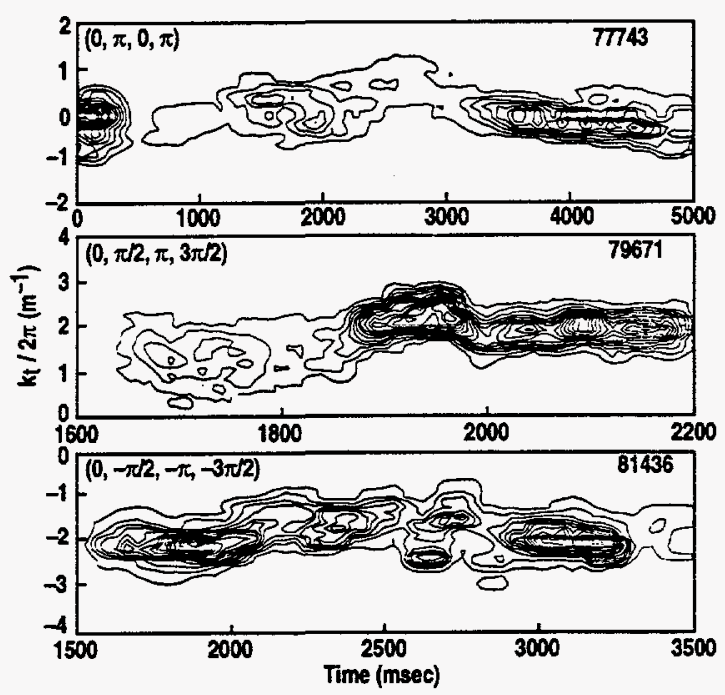

FIGURE 3. The wavenumber $\left(k_{\mathrm{t}} / 2 \pi\right)$ distributions obtained from three different phasings: (a) $(0,0,0,0),(b)(0, \pi / 2, \pi,-\pi / 2)$, and (c) $(0,-\pi / 2, \pi, \pi / 2)$.

power portions are contributed by more than single turn signals. All of our data (several hundred plasma shots) show that $k_{\mathrm{t}}$ is down-shifted and the spectrum is broader after the ray travels a longer distance. In some cases, it is almost one-half the value of a single toroidal turn signal. The $(0,0,0,0)$ phasing introduces the spectra centered near $k_{\mathrm{t}}=0$. Again, $k_{\mathrm{t}} R$ is not a constant as we find in Fig. 3(a).

This is a report of work sponsored by the U.S. Department of Energy under Contract No. DE-AC03-89ER51114.

\section{REFERENCES}

[1] J.S. deGrassie, "Fast Wave Current Drive on DIII-D," this conference.

[2] T.K. Mau et al., in Proc. Europhys. Top. Conf. on Radiofrequency Heating and Current Drive in Fusion Devices, Brussels, 1992, p. 181.

[3] M. Brambilla and T. Krucken, Nucl. Fusion 28, 1813 (1988). 